\title{
Effect of Heat Treatment and Bath Process Parameters on the Corrosion Behavior of Ni-P-TiO ${ }_{2}$ Composite Coatings
}

\author{
Prasanna Gadhari and Prasanta Sahoo* \\ Department of Mechanical Engineering, Jadavpur University, Kolkata, 700032, India
}

Received 10 June 2015; accepted 20 June 2015

\begin{abstract}
The present research article deals with the study of corrosion behavior of $\mathrm{Ni}-\mathrm{P}-\mathrm{TiO}_{2}$ composite coating. The $\mathrm{TiO}_{2}$ composite coating is deposited on the mild steel substrate. Corrosion behavior of the $\mathrm{TiO}_{2}$ composite coatings after heat treatment at various annealing temperatures $\left(300{ }^{\circ} \mathrm{C}, 400{ }^{\circ} \mathrm{C}\right.$, and $\left.500{ }^{\circ} \mathrm{C}\right)$ is evaluated with the help of potentiodynamic polarization test using $3.5 \% \mathrm{NaCl}$ solution. The electrochemical parameters, corrosion potential $\left(E_{\text {corr }}\right)$ and corrosion current density $\left(I_{\text {corr }}\right)$, are optimized for maximum corrosion resistance using Taguchi based grey relational analysis. The coating parameters, namely, nickel sulphate, sodium hypophosphite, concentration of $\mathrm{TiO}_{2}$ particles and annealing temperature are considered as main design factors. The analysis of variance (ANOVA) revealed that the annealing temperature and concentration of $\mathrm{TiO}_{2}$ particles have significant influence on the corrosion behavior of the composite coating. The microstructure characterization of the coating is conducted using scanning electron microscopy, energy dispersive X-ray analysis and X-ray diffraction analysis. The Ni-P-TiO ${ }_{2}$ composite coating exhibits nodular structure with uniform incorporation of titanium particles and converts into the crystalline structure after heat treatment.
\end{abstract}

Keywords: $\mathrm{Ni}-\mathrm{P}-\mathrm{TiO}_{2}$ composite coating, corrosion, potentiodynamic polarization, optimization.

\section{Introduction}

In industries, it is big challenge to protect the components and parts from corrosion and wear. Hence, it is essential to develop the suitable materials which have higher corrosion and wear resistance. But, it is not economical to produce such materials, which have excellent tribological properties. Deposition of additional layer on the surface of the component is the effective way to improve

\footnotetext{
* Corresponding author. E-mail address: psjume@gmail.com, psahoo@mech.jdvu.ac.in
} 
the mechanical and tribological properties of the component with greater economical balance. The additional layer is produced with the help of the coating. Electroless nickel (EN) coating is an autocatalytic chemical technique to deposit layer of Ni-P/Ni-B on the surface of the metal or non-metal without using electric current. The electroless nickel-phosphorus coatings have excellent corrosion and wear resistance properties [1-4]. The EN coatings with higher phosphorus content have higher corrosion resistance. Hence, these coatings are mostly used in corrosive environments such as oil and gas industry, mining, chemical, and structural components, etc. Similarly, the corrosion resistance of the composite coatings is increased with increase in the content of composite particles [5]. In present days, electroless nickel coatings have gained wide popularity in automobile, mechanical, aerospace, chemical, electronic, printing, textile and in scientific domain, due to their excellent tribological properties.

The EN composite coatings have better corrosion properties. The composite coatings in which second phase particles are uniformly distributed have excellent corrosion protection. Second phase particles reduce the metallic area of the coated surface and forms a physical barrier to resist the corrosion process [6-12]. On the other hand, composite coatings deposited with non-uniform distribution of second phase particles have lower corrosion resistance. Due to non-uniform distribution of particles, the coating structure becomes porous [13]. In case of soft composite coatings, the coating structure becomes dense and more homogeneous after heat treatment, which results in improvement in corrosion resistance compared to as-deposited soft coatings [14-16]. In most of the cases, heat treated composite coatings exhibited excellent corrosion resistance compared to as-deposited composite coatings. Heat treatment improves the density and structure of the coating, which results in decrease in porosity of the composite coating [17-19].

Generally, corrosion resistance of the Ni-P coatings depends on the rate of dissolution of the passive film apart from the amount of the phosphorus present in the coatings. In case of composite coatings it is observed that the formation of the passive layer is disturbed by the second phase particles which results into decrease in corrosion resistance of the composite coatings. Phosphorus present on the coated surface plays a vital role in corrosion resistance. An EN composite coating with higher phosphorus content shows excellent corrosion resistance, as the phosphide particles enables preferential hydrolysis of phosphorus over nickel [20]. The composite coating deposited using sol-gel technique has excellent corrosion resistance compared to conventional composite coatings and Ni-P coatings [21]. Surfactant present in the electroless bath reduces agglomeration of second phase particles, which results in uniform distribution of particles in the coated layer. Hence, surfactants improve the corrosion resistance of the composite coatings [22-23].

Corrosion behavior of electroless nickel coatings studies are achieved using electrochemical tests, namely, potentiodynamic polarization test and electrochemical impedance spectroscopy test. The resistance of the coatings towards corrosion is evaluated on the basis of the corrosion parameters obtained from corrosion potential $\left(E_{c o r r}\right)$, corrosion current density $\left(I_{c o r r}\right)$, charge transfer 
resistance $\left(R_{c t}\right)$, double-layer capacitance $\left(C_{d l}\right)$, and corrosion rate $\left(R_{c}\right)$, etc. The present study deals with the evaluation of corrosion behavior of the $\mathrm{Ni}-\mathrm{P}-\mathrm{TiO}_{2}$ composite coating using potentiodynamic polarization tests. The Taguchi method with grey relational analysis has been employed to optimize the process parameters in order to find the optimum combination of coating parameters, which improve the electrochemical properties of the coatings. Analysis of variance (ANOVA) is used to observe the level of significance of the factors and their interactions. In the last, confirmation test is conducted to validate the test results. The surface morphology and composition of $\mathrm{Ni}-\mathrm{P}-\mathrm{TiO}_{2}$ coatings have been studied with the help of scanning electron microscopy (SEM), energy dispersed X-ray analysis (EDX) and X-ray diffraction analysis (XRD).

\section{Materials and methods}

\section{Preparation of the substrate and electroless composite bath}

In the present work AISI 1040 (mild steel) is used as substrate material with size $20 \mathrm{~mm} \times 20 \mathrm{~mm} \times 2 \mathrm{~mm}$. Effective deposition of the coating on the substrate depends on the preparation of the substrate. Hence, it is essential to prepare the surface of the substrate carefully and properly. Different machining processes such as shaping, parting, milling and grinding have been used in the given sequence to prepare the square shape substrates. Initially, the substrate was cleaned with the help of de-ionized water to remove foreign particles. Before coating process, the substrate is subjected to pickling treatment to remove the layer formed due to rust and other oxides. After that the substrate is rinsed with de-ionized water and cleaned with methanol. In the initial stage of the coating deposition process, the substrate is activated in warm palladium chloride solution to increase the coating deposition rate. After that, the activated substrate is immediately dipped in the hot electroless bath, maintained at $85{ }^{\circ} \mathrm{C}$. The coating deposition process is carried out for three hours. For each substrate the constant deposition time is maintained to obtain uniform thickness of the coating. The coating thickness has been found in the range of 25 to 29 microns.

Fig. 1 shows the experimental setup for electroless $\mathrm{Ni}-\mathrm{P}-\mathrm{TiO}_{2}$ composite coating. The setup consists of heater cum magnetic stirrer (IKA ${ }^{\circledR}$ RCT basic) with temperature range from 0 to $310{ }^{\circ} \mathrm{C}$ and the stirrer speed range from 0 to 1500 $\mathrm{rpm}$. A fixed rigid stand was provided to hold and support the substrate and the glass coated temperature sensor. A glass beaker $(250 \mathrm{~mL})$ containing the electroless bath $(200 \mathrm{~mL})$ was put on the heating plate for coating deposition. With the help of a temperature sensing knob, the temperature was set up to $85^{\circ} \mathrm{C}$ and the stirrer speed set with the help of the speed setting knob at $300 \mathrm{rpm}$. The important function of PTFE coated magnetic stirrer is to maintain the $\mathrm{TiO}_{2}$ particles in suspension without agglomeration in the electroless bath. The stirrer speed is fixed after a large number of iterations to avoid the decomposition of the electroless bath due to the agglomeration of particles.

It is very important to select the appropriate process parameters (chemicals and other factors) along with their quantity. The bath composition and operating conditions for electroless $\mathrm{TiO}_{2}$ composite coatings are selected after various 
experiments, and the proper range of the parameters is chosen accordingly. The three most important parameters (nickel source, reducing agent, and concentration of $\mathrm{TiO}_{2}$ particles) are varied and the other parameters kept constant for the coating deposition. To understand the effect of heat treatment on corrosion resistance, the coated substrates are heat treated in a muffle furnace for one hour at different temperatures $\left(300{ }^{\circ} \mathrm{C}, 400{ }^{\circ} \mathrm{C}\right.$, and $\left.500{ }^{\circ} \mathrm{C}\right)$ according to the Orthogonal Array (OA). After heat treatment, the substrates are cooled down to room temperature in the furnace without application of any artificial cooling. The bath composition and operating conditions of the electroless $\mathrm{Ni}-\mathrm{P}-\mathrm{TiO}_{2}$ composite coatings are shown in Table 1.

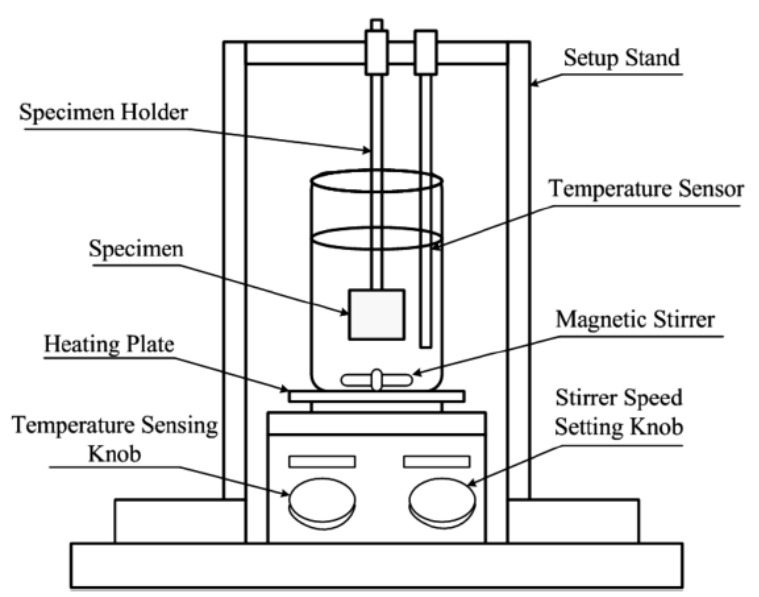

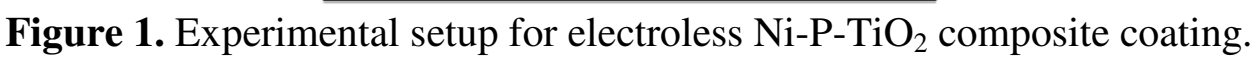

Table 1. Chemical composition and working conditions for the electroless bath.

\begin{tabular}{lccc}
\hline Bath chemical composition & Quantity & \multicolumn{2}{c}{ Working conditions } \\
\hline $\mathrm{NiSO}_{4} \cdot 6 \mathrm{H}_{2} \mathrm{O}$ (Nickel sulphate) & $35-45 \mathrm{~g} / \mathrm{L}$ & $\mathrm{pH}$ & $4.5-5.0$ \\
$\mathrm{NaH}_{2} \mathrm{PO}_{2} \cdot 2 \mathrm{H}_{2} \mathrm{O}$ (Sodium hypophosphite) & $15-25 \mathrm{~g} / \mathrm{L}$ & Bath temperature & $85 \pm 2{ }^{\circ} \mathrm{C}$ \\
$\mathrm{TiO}_{2}$ particles & $5-15 \mathrm{~g} / \mathrm{L}$ & Bath volume & $250 \mathrm{~mL}$ \\
$\mathrm{C}_{6} \mathrm{H}_{5} \mathrm{Na}_{3} \mathrm{O}_{7} \cdot 2 \mathrm{H}_{2} \mathrm{O}$ (Tri sodium citrate) & $15 \mathrm{~g} / \mathrm{L}$ & Stirrer speed & $300 \mathrm{rpm}$ \\
$\mathrm{CH}_{3} \mathrm{COONa}$ (Sodium acetate) & $5 \mathrm{~g} / \mathrm{L}$ & Deposition time & 3 hours \\
$\mathrm{C}_{12} \mathrm{H}_{25} \mathrm{NaO}_{4} \mathrm{~S}$ (Sodium dodecyl sulphate) & $0.2 \mathrm{~g} / \mathrm{L}$ & Annealing temperature & $300-500{ }^{\circ} \mathrm{C}$ \\
\hline
\end{tabular}

\section{Role of coating parameters and working conditions in the electroless bath}

In the electroless bath, nickel sulphate is used as nickel source (it supplies nickel ions in the solution) and sodium hypophosphite is used as reducing agent which reduces the nickel ions from their positive valence state to zero valence state. At $85{ }^{\circ} \mathrm{C}$ bath temperature, the rapid and fast chemical reaction between the nickel source and the reducing agent results in immediate decomposition of the electroless bath. In such case, complexing agents are used to avoid decomposition of the bath. Sometime bath gets decomposed even though complexing agents are present in the electroless bath; in such situation, stabilizers play an important role to avoid the bath decomposition.

Surfactants are used to increase the wettability and surface charge of the second phase particles [24]. Surfactant reduces the surface tension of the liquid and 
interfacial tension between solid and liquid particles. It also reduces the agglomeration of the second phase particles and adsorption of suspended particles on the specimen [25]. Approximately $50 \mathrm{~mL}$ of electroless bath solution containing specified amount of $\mathrm{TiO}_{2}$ particles and SDS are thoroughly mixed using a magnetic stirrer (Remi make $2 \mathrm{MLH}$ ) for better suspension of particles in the electroless bath. At first Ni-P coating is deposited for one hour to prevent the porosity of the coating, then the slurry of $\mathrm{TiO}_{2}$ particles, SDS and electroless bath $(50 \mathrm{~mL})$ are introduced into the same bath for the subsequent two hours to deposit the $\mathrm{TiO}_{2}$ composite coating.

\section{Potentiodynamic polarization test}

The potentiodynamic polarization tests of heat treated electroless $\mathrm{Ni}-\mathrm{P}-\mathrm{TiO}_{2}$ composite coated substrates are carried out using a potentiostat [(Gill AC) of ACM instrument, U. K.] with $3.5 \% \mathrm{NaCl}$ solution at ambient temperature (33 $\left.{ }^{\circ} \mathrm{C}\right)$. The electrochemical cell consists of three electrodes. A saturated calomel electrode (SCE) is used as reference electrode, which provides a stable 'reference' against which the applied potential is accurately measured. A platinum electrode is used as counter electrode or auxiliary electrode, which provides the path for the applied current into the electrolyte solution. The coated specimen is used as working electrode. The design of the cell is such that only an area of $1 \mathrm{~cm}^{2}$ of the coated surface is exposed to the electrolyte.

The experimental setup of the potentiodynamic polarization test is shown in Fig. 2. A settling time of 15 minutes is assigned before every test in order to stabilize the open circuit potential (OCP). The potentiostat is controlled with the help of a personnel computer, which also stores the polarization data. The polarization curve is obtained from dedicated software, which also possesses a special tool in order to extrapolate the values of corrosion potential and corrosion current density from the plot. A Tafel ruler is provided with associated software to measure the corrosion potential and corrosion current density. A horizontal ruler is matched at the junction of the cathodic and anodic branches. This point gives the value of the corrosion potential and the corrosion current density is obtained by extrapolating the fitting lines of the anodic and cathodic branches of the Tafel curve.

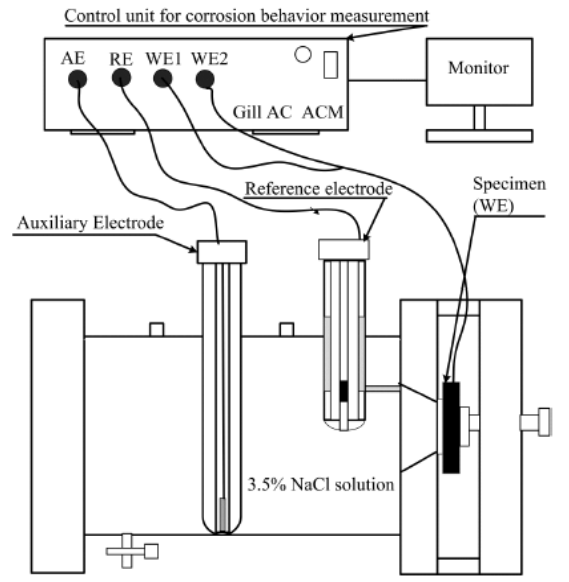

Figure 2. Experimental setup for potentiodynamic polarization test. 


\section{Microstructure study and characterization of $\mathrm{Ni}-\mathrm{P}-\mathrm{TiO}_{2}$ composite coating}

Energy dispersive X-ray analysis (EDAX Corporation) is used to verify and find out the presence of nickel, phosphorus, titanium, and oxygen in the composite coating in terms of weight percentage. Scanning electron microscopy (JEOL, JSM-6360) is used to observe the surface morphology of the composite coating before and after heat treatment $\left(400{ }^{\circ} \mathrm{C}\right)$. This is done in order to analyze the effect of heat treatment on the surface structure of electroless $\mathrm{Ni}-\mathrm{P}-\mathrm{TiO}_{2}$ composite coatings. An X-ray diffraction analyzer (Rigaku, Ultima III) is used to find out the phase composition of as-deposited and heat treated composite coatings.

\section{Coating process optimization and planning of experiment}

The design factors or input parameters (experimental parameters) are varied within the specific range to obtain a desired result of the response variables (output parameters). The aim of the study is to obtain an optimum combination of the design factors for the best possible value of response variables. There are many factors which are considered to improve the corrosion behavior of Ni-P$\mathrm{TiO}_{2}$ composite coatings. On the basis of literature review [26-29] the most influential process parameters are selected to improve the electrochemical performance of the composite coating. In the present work, nickel sulphate (A), sodium hypophosphite (B), concentration of $\mathrm{TiO}_{2}$ particles (C) and annealing temperature (D) are considered as process parameters due to their effect on corrosion resistance. Table 2 shows the design factors along with their levels. In the present experiment, four process parameters are used with three levels; therefore the total degrees of freedom (DOF) considering the individual factors and their interaction are 20. Hence the $\boldsymbol{L}_{27}$ orthogonal array (OA) is chosen which has 27 rows corresponding to the number of experiments and 26 DOF with 13 columns. The $\boldsymbol{L}_{27}$ OA is shown in Table 3. Each row in the table represents the specific combination of experimental run and each column represents a specific factor or interactions. The cell value indicates the level of corresponding factor or interaction assigned to that column. The experimental run is controlled by the setting of the design factors and not by the interactions.

Table 2. Design parameters and their levels.

\begin{tabular}{llllll}
\hline \multirow{2}{*}{ Design factors } & Designation & \multirow{2}{*}{ Unit } & \multicolumn{3}{c}{ Levels } \\
\cline { 4 - 6 } & & & $\mathbf{1}$ & $\mathbf{2}$ & $\mathbf{3}$ \\
\hline $\mathrm{NiSO}_{4} \cdot 6 \mathrm{H}_{2} \mathrm{O}$ (Nickel sulphate) & $\mathrm{A}$ & $\mathrm{g} / \mathrm{L}$ & 35 & $40^{*}$ & 45 \\
$\mathrm{NaH}_{2} \mathrm{PO}_{2} \cdot 2 \mathrm{H}_{2} \mathrm{O}$ (Sodium hypophosphite) & $\mathrm{B}$ & $\mathrm{g} / \mathrm{L}$ & 15 & $20^{*}$ & 25 \\
$\mathrm{TiO}_{2}$ particles concentration & $\mathrm{C}$ & $\mathrm{g} / \mathrm{L}$ & 5 & $10^{*}$ & 15 \\
Annealing temperature & $\mathrm{D}$ & ${ }^{\circ} \mathrm{C}$ & 300 & $400^{*}$ & 500 \\
\hline$*$ * initial condition & & & & & \\
\hline
\end{tabular}

The aim of the present study is to improve corrosion potential and to reduce the corrosion current density of the $\mathrm{TiO}_{2}$ composite coating. Hence, it becomes a multiple response problem of optimization which cannot be solved only by Taguchi technique [30], because it may be possible that higher $\mathrm{S} / \mathrm{N}$ ratio of one 
response corresponds to the lower $\mathrm{S} / \mathrm{N}$ ratio of the other. Grey relational analysis [31] is used for overall evaluation of the $\mathrm{S} / \mathrm{N}$ ratio to optimize the multiple response characteristics. The optimization process is performed in number of stages. In the first stage, the experimental results are normalized in the range of one and zero. Grey relational generation and grey relational coefficients are calculated using normalized data. The normalized data represent the correlation between actual experimental data and the desired experimental data. In the third stage grey relational grade is calculated by averaging the grey relational coefficients. The grey relational grade is treated as the overall response of the process instead of multiple responses of corrosion potential and corrosion current density.

Table 3. Design factors and interactions in $L_{27}$ orthogonal array.

\begin{tabular}{lccccccccccccc}
\hline Trial No. & & & \multicolumn{10}{c}{ Column numbers } & \multicolumn{1}{c}{ (1) } \\
\hline & 1 & 2 & 3 & 4 & 5 & 6 & 7 & 8 & 9 & 10 & 12 & 13 \\
& A & B & AxB & AxB & C & AxC & AxC & BxC & D & & BxC & & \\
\hline 1 & & 1 & 1 & 1 & 1 & 1 & 1 & 1 & 1 & 1 & 1 & 1 & 1 \\
2 & 1 & 1 & 1 & 1 & 2 & 2 & 2 & 2 & 2 & 2 & 2 & 2 & 2 \\
3 & 1 & 1 & 1 & 1 & 3 & 3 & 3 & 3 & 3 & 3 & 3 & 3 & 3 \\
4 & 1 & 2 & 2 & 2 & 1 & 1 & 1 & 2 & 2 & 2 & 3 & 3 & 3 \\
5 & 1 & 2 & 2 & 2 & 2 & 2 & 2 & 3 & 3 & 3 & 1 & 1 & 1 \\
6 & 1 & 2 & 2 & 2 & 3 & 3 & 3 & 1 & 1 & 1 & 2 & 2 & 2 \\
7 & 1 & 3 & 3 & 3 & 1 & 1 & 1 & 3 & 3 & 3 & 2 & 2 & 2 \\
8 & 1 & 3 & 3 & 3 & 2 & 2 & 2 & 1 & 1 & 1 & 3 & 3 & 3 \\
9 & 1 & 3 & 3 & 3 & 3 & 3 & 3 & 2 & 2 & 2 & 1 & 1 & 1 \\
10 & 2 & 1 & 2 & 3 & 1 & 2 & 3 & 1 & 2 & 3 & 1 & 2 & 3 \\
11 & 2 & 1 & 2 & 3 & 2 & 3 & 1 & 2 & 3 & 1 & 2 & 3 & 1 \\
12 & 2 & 1 & 2 & 3 & 3 & 1 & 2 & 3 & 1 & 2 & 3 & 1 & 2 \\
13 & 2 & 2 & 3 & 1 & 1 & 2 & 3 & 2 & 3 & 1 & 3 & 1 & 2 \\
14 & 2 & 2 & 3 & 1 & 2 & 3 & 1 & 3 & 1 & 2 & 1 & 2 & 3 \\
15 & 2 & 2 & 3 & 1 & 3 & 1 & 2 & 1 & 2 & 3 & 2 & 3 & 1 \\
16 & 2 & 3 & 1 & 2 & 1 & 2 & 3 & 3 & 1 & 2 & 2 & 3 & 1 \\
17 & 2 & 3 & 1 & 2 & 2 & 3 & 1 & 1 & 2 & 3 & 3 & 1 & 2 \\
18 & 2 & 3 & 1 & 2 & 3 & 1 & 2 & 2 & 3 & 1 & 1 & 2 & 3 \\
19 & 3 & 1 & 3 & 2 & 1 & 3 & 2 & 1 & 3 & 2 & 1 & 3 & 2 \\
20 & 3 & 1 & 3 & 2 & 2 & 1 & 3 & 2 & 1 & 3 & 2 & 1 & 3 \\
21 & 3 & 1 & 3 & 2 & 3 & 2 & 1 & 3 & 2 & 1 & 3 & 2 & 1 \\
22 & 3 & 2 & 1 & 3 & 1 & 3 & 2 & 2 & 1 & 3 & 3 & 2 & 1 \\
23 & 3 & 2 & 1 & 3 & 2 & 1 & 3 & 3 & 2 & 1 & 1 & 3 & 2 \\
24 & 3 & 2 & 1 & 3 & 3 & 2 & 1 & 1 & 3 & 2 & 2 & 1 & 3 \\
25 & 3 & 3 & 2 & 1 & 1 & 3 & 2 & 3 & 2 & 1 & 2 & 1 & 3 \\
26 & 3 & 3 & 2 & 1 & 2 & 1 & 3 & 1 & 3 & 2 & 3 & 2 & 1 \\
27 & 3 & 3 & 2 & 1 & 3 & 2 & 1 & 2 & 1 & 3 & 1 & 3 & 2 \\
\hline
\end{tabular}

\section{Results and discussion}

Surface morphology and characterization of $\mathrm{Ni}-\mathrm{P}-\mathrm{TiO}_{2}$ composite coating

The characterization of the coating is vital to check the content of elements in the composite coating. Energy dispersive X-ray analysis (EDX) is used to find the existence of coating elements in terms of weight percentage. Table 4 shows the EDX result of Ni-P-TiO 2 composite coatings at different concentration of $\mathrm{TiO}_{2}$ particles in the electroless bath. Fig. 3 shows the EDX plots for $\mathrm{TiO}_{2}$ composite coatings, with different concentrations of $\mathrm{TiO}_{2}$ particles $(5 \mathrm{~g} / \mathrm{L}$ and $10 \mathrm{~g} / \mathrm{L})$ in the 
electroless bath. From EDX plots and the tabulated results it is confirmed that the weight percentage of titanium particles in the coating is increased (from 6.41 wt.\% to 9.97 wt.\%) with increase in concentration of $\mathrm{TiO}_{2}$ particles in the electroless bath. At the same time, weight percentage of nickel (80.72 to $75.17 \%)$ and phosphorus (8.13 to $7.74 \%$ ) decreased and oxygen increased from $4.74 \%$ to $7.12 \%$.

Table 4. EDX results of Ni-P-TiO 2 composite coatings.

\begin{tabular}{llccccc}
\hline Figure No. & $\begin{array}{l}\text { Concentration of } \\
\mathrm{TiO}_{2} \text { particles }\end{array}$ & \% of Ni & \% of $\mathbf{P}$ & \% of $\mathbf{O}$ & \% of Ti & Total \\
\hline Figure 3 (a) & $5 \mathrm{~g} / \mathrm{L}$ & 80.72 & 8.13 & 4.74 & 6.41 & 100 \\
Figure 3 (b) & $10 \mathrm{~g} / \mathrm{L}$ & 75.17 & 7.74 & 7.12 & 9.97 & 100 \\
\hline
\end{tabular}

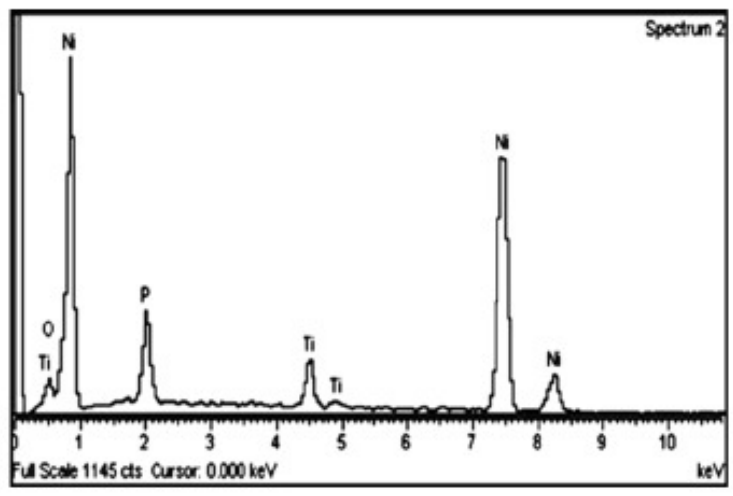

(a)

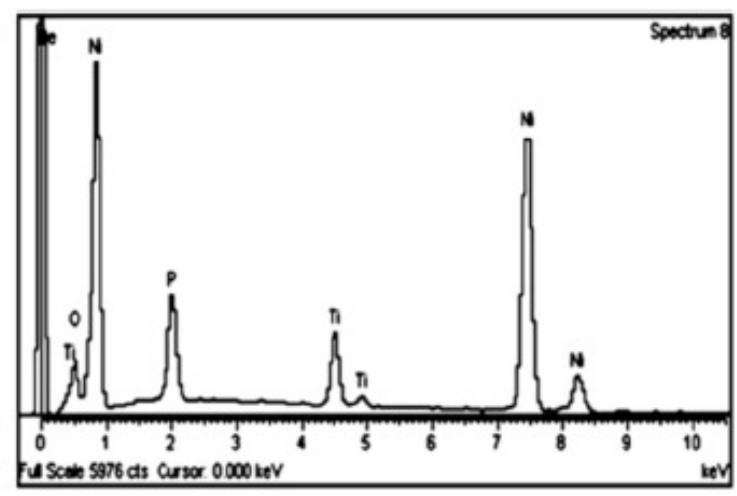

(b)

Figure 3. EDX of $\mathrm{Ni}-\mathrm{P}-\mathrm{TiO}_{2}$ composite coating with (a) $5 \mathrm{~g} / \mathrm{L}$ and (b) $10 \mathrm{~g} / \mathrm{L}$ of $\mathrm{TiO}_{2}$.

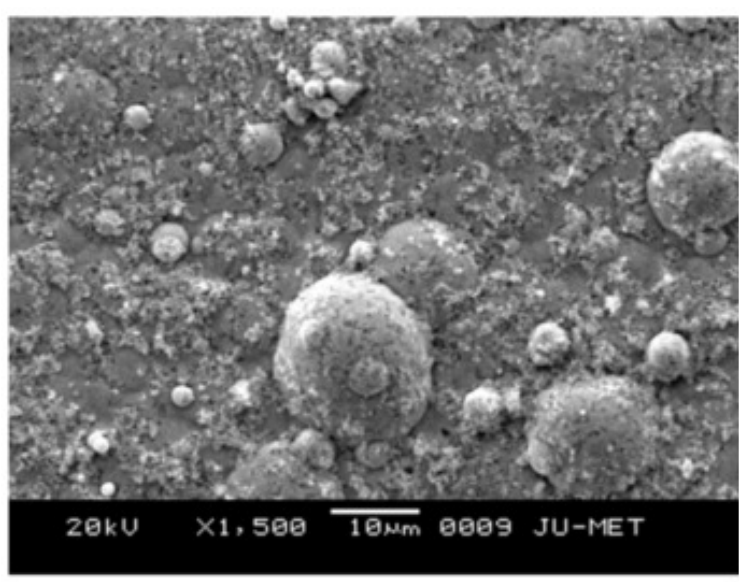

(a)

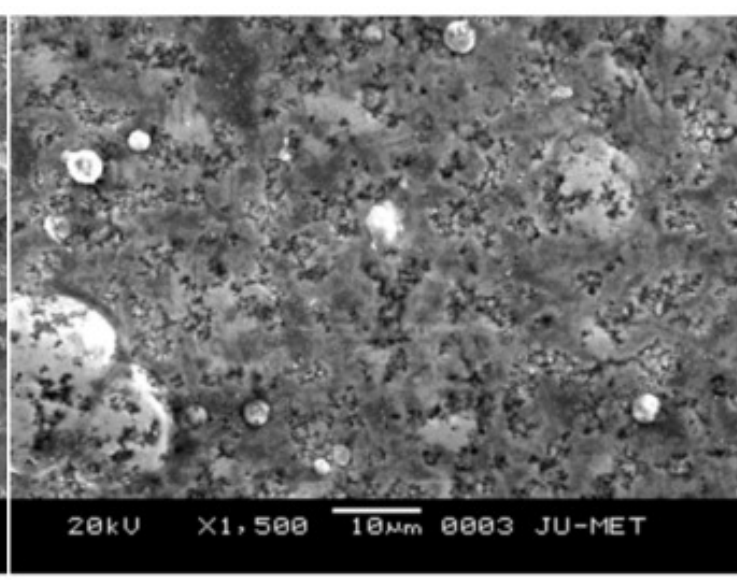

(b)

Figure 4. SEM images of $\mathrm{Ni}-\mathrm{P}-\mathrm{TiO}_{2}$ composite coatings: (a) as-deposited; (b) heat treated at $400{ }^{\circ} \mathrm{C}$.

The SEM images of as-deposited and heat-treated Ni-P-TiO $\mathrm{N}_{2}$ composite coatings are shown in Fig. 4. The surface of the as-deposited coated substrate (Fig. 4a) shows typical nodular structure with uniform distribution of titanium particles. Fig. 4(b) shows the SEM micrographs of heat treated Ni-P-TiO ${ }_{2}$ composite coatings at $400{ }^{\circ} \mathrm{C}$. From this figure, it is confirmed that the grain structure of the 
heat-treated composite coatings is changed due to the heat treatment. Also by careful observation, it is noticed that the grains are coarsened due to heat treatment at $400{ }^{\circ} \mathrm{C}$. At this temperature, crystallization of nickel and precipitation of phosphide $\left(\mathrm{Ni}_{3} \mathrm{P}\right)$ occur, which reduces the porosity of the coating, resulting in increase in corrosion resistance.

Fig. 5 shows the X-ray diffraction plots for $\mathrm{Ni}-\mathrm{P}-\mathrm{TiO}_{2}$ composite coatings in asdeposited and heat-treated condition $\left(400{ }^{\circ} \mathrm{C}\right)$. Fig. 5(a) shows XRD plot for asdeposited $\mathrm{TiO}_{2}$ composite coating. A single broad peak at 44.24 diffraction angle confirmed the amorphous structure of as-deposited composite coating. Fig. 5(b) shows the XRD plot for heat treated (at $400{ }^{\circ} \mathrm{C}$ ) $\mathrm{TiO}_{2}$ composite coating. From the plot it is confirmed that the amorphous structure of the composite coating converted in the crystalline structure. Due to heat treatment, peaks of $\mathrm{Ni}_{3} \mathrm{P}$ (hard particles) are seen at various diffraction angles. These particles are responsible for increase in hardness and wear resistance of $\mathrm{TiO}_{2}$ composite coatings.

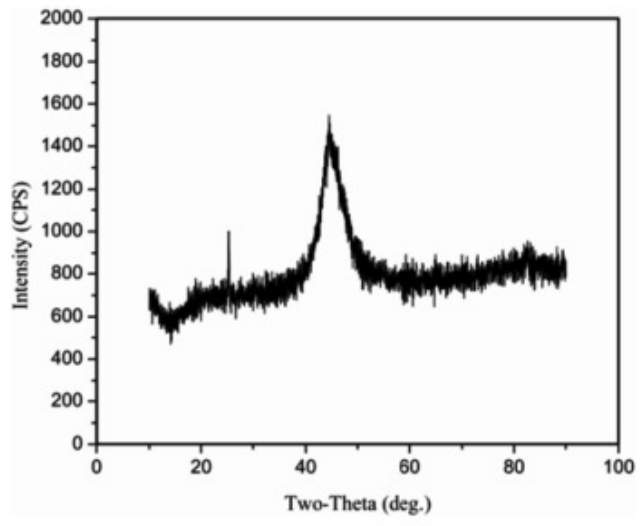

(a)

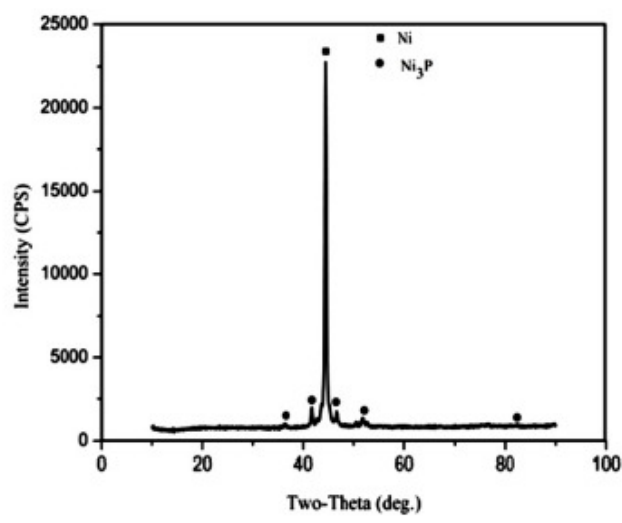

(b)

Figure 5. XRD plots for Ni-P-TiO ${ }_{2}$ composite coating in (a) as-deposited phase, (b) heat treated at $400{ }^{\circ} \mathrm{C}$.

\section{Optimization of corrosion parameters and confirmation test}

The experimental values of $E_{\text {corr }}$ and $I_{\text {corr }}$ are shown in Table 5. The present work deals with two responses, corrosion potential and corrosion current density, for optimization of corrosion behavior of $\mathrm{Ni}-\mathrm{P}-\mathrm{TiO}_{2}$ composite coatings. Grey analysis technique converts a multi response (variable) problem in a single response problem. The particular sets of analysis performed to convert the given multiple responses in single performance index, is called as grey relational grade. For excellent electrochemical performance, higher value of corrosion potential and lower value of corrosion current density are preferred. Hence, higher-thebetter criterion used for corrosion potential and lower-the-better criterion is used for corrosion current density. The equations for the higher-the-better and lowerthe-better criteria are given below,

Equation for higher-the-better

$$
x_{i}(k)=\frac{y_{i}(k)-\min y_{i}(k)}{\max y_{i}(k)-\min y_{i}(k)}
$$


Table 5. Experimental values of corrosion potential and corrosion current density.

\begin{tabular}{llllll}
\hline Sr. No. & $\boldsymbol{E}_{\text {corr }}(\mathbf{m V})$ & $\boldsymbol{I}_{\text {corr }}\left(\boldsymbol{\mu} \mathbf{A} / \mathbf{c m}^{2}\right)$ & Sr. No. & $\boldsymbol{E}_{\text {corr }}(\mathbf{m V})$ & $\boldsymbol{I}_{\text {corr }}\left(\boldsymbol{\mu} \mathbf{A} / \mathbf{c m}^{2}\right)$ \\
\hline 1 & -441.52 & 0.0020037 & 15 & -323.94 & 0.0002988 \\
2 & -356.65 & 0.0003579 & 16 & -425.33 & 0.0005225 \\
3 & -309.46 & 0.00007314 & 17 & -341.09 & 0.0001665 \\
4 & -386.66 & 0.0003769 & 18 & -364.15 & 0.0001217 \\
5 & -340.8 & 0.0000967 & 19 & -418.95 & 0.0001451 \\
6 & -322.26 & 0.0009169 & 20 & -383.69 & 0.000913 \\
7 & -466.68 & 0.0017709 & 21 & -331.37 & 0.0001948 \\
8 & -390.35 & 0.0001818 & 22 & -371.63 & 0.0001826 \\
9 & -337.15 & 0.0001365 & 23 & -315.64 & 0.00004909 \\
10 & -331.24 & 0.0000915 & 24 & -336.41 & 0.0002869 \\
11 & -418.63 & 0.0001542 & 25 & -339.54 & 0.0003502 \\
12 & -394.91 & 0.000586 & 26 & -331.09 & 0.0001711 \\
13 & -421.47 & 0.0001586 & 27 & -366.37 & 0.0001028 \\
14 & -346.06 & 0.0007794 & & & \\
\hline
\end{tabular}

Equation for lower-the-better

$$
x_{i}(k)=\frac{\max y_{i}(k)-y_{i}(k)}{\max y_{i}(k)-\min y_{i}(k)}
$$

where $x_{i}(k)$ is the normalized value after grey relational generation, while $\min y_{i}(k)$ and $\max y_{i}(k)$ are, respectively, the smallest and largest values of $y_{i}(k)$ for the $k^{\text {th }}$ response, with $k=1$ for corrosion potential and $k=2$ for corrosion current density. Larger normalized results correspond to excellent performance and the best normalized result should equal to one. All the normalized values and grey relational coefficients are shown in Table 6.

The grey relational coefficient is calculated from the normalized value and the equation for the grey relational coefficient is given as below,

$$
\xi_{i}(k)=\frac{\Delta_{\min }+r \xi \Delta_{\max }}{\Delta_{o i}(k)+r \xi \Delta_{\max }}
$$

where $\Delta_{o i}=\left\|x_{o}(k)-x_{i}(k)\right\|$ is the difference of the absolute value between $x_{o}(k)$ and $x_{i}(k) . \Delta_{\min }$ and $\Delta_{\max }$ are the minimum and maximum values of the absolute differences $\left(\Delta_{o i}\right)$ of all comparing sequences. ' $r$ ' is the distinguishing coefficient which is used to adjust the difference of the relational coefficient in the range of 0 to 1 . The suggested value of the distinguishing coefficient is 0.5 . The overall multiple response characteristics evaluation is based on grey relational grade and it is calculated as follows:

$$
\gamma_{i}=\frac{1}{n} \sum_{i=1}^{n} \xi_{i}(k)
$$


where $n$ is the number of process responses. The grey relational grades are considered in the optimization of multi-response parameter design problem. The values of grey relational grade are shown in Table 7.

Table 6. Grey relational analysis for corrosion potential and corrosion current density.

\begin{tabular}{|c|c|c|c|c|c|c|}
\hline \multirow{2}{*}{$\begin{array}{l}\text { Sr. } \\
\text { No. }\end{array}$} & \multicolumn{2}{|c|}{ Normalized value } & \multicolumn{2}{|c|}{$\Delta$ value } & \multicolumn{2}{|c|}{ Grey coefficient } \\
\hline & $E_{\text {corr }}$ & $I_{c o r r}$ & $E_{c o r r}$ & $I_{c o r r}$ & $E_{\text {corr }}$ & $I_{\text {corr }}$ \\
\hline 1 & 0.16003053 & 0.000000000 & 0.83997 & 1.0000000 & 0.37314283 & 0.333333333 \\
\hline 2 & 0.699847348 & 0.842009403 & 0.30015 & 0.1579906 & 0.624880763 & 0.759889279 \\
\hline 3 & 1.000000000 & 0.987695755 & 0.00000 & 0.01230424 & 1.000000000 & 0.975982544 \\
\hline 4 & 0.508968325 & 0.832288794 & 0.49103 & 0.16771121 & 0.504524742 & 0.748826732 \\
\hline 5 & 0.800661493 & 0.9756422 & 0.19934 & 0.0243578 & 0.714961346 & 0.953547367 \\
\hline 6 & 0.918585422 & 0.556018848 & 0.08141 & 0.44398115 & 0.859971557 & 0.529671592 \\
\hline 7 & 0.000000000 & 0.119103044 & 1.00000 & 0.88089696 & 0.333333333 & 0.362083498 \\
\hline 8 & 0.485498028 & 0.932104103 & 0.5145 & 0.0678959 & 0.492852665 & 0.880443057 \\
\hline 9 & 0.823877369 & 0.955280081 & 0.17612 & 0.04471992 & 0.739510818 & 0.917902913 \\
\hline 10 & 0.861468007 & 0.978302577 & 0.13853 & 0.02169742 & 0.78304612 & 0.958409948 \\
\hline 11 & 0.305622694 & 0.946224567 & 0.69438 & 0.05377543 & 0.418628182 & 0.902893068 \\
\hline 12 & 0.456494085 & 0.725310932 & 0.54351 & 0.27468907 & 0.479153968 & 0.645420234 \\
\hline 13 & 0.287558835 & 0.943973478 & 0.71244 & 0.05602652 & 0.412391145 & 0.899237681 \\
\hline 14 & 0.76720519 & 0.626365362 & 0.23279 & 0.37363464 & 0.682319243 & 0.57232163 \\
\hline 15 & 0.907899758 & 0.872245614 & 0.0921 & 0.12775439 & 0.844451606 & 0.796489855 \\
\hline 16 & 0.263007251 & 0.757798231 & 0.73699 & 0.24220177 & 0.404206088 & 0.673671259 \\
\hline 17 & 0.798816944 & 0.939931751 & 0.20118 & 0.06006825 & 0.713080552 & 0.892748341 \\
\hline 18 & 0.652143493 & 0.962851924 & 0.34786 & 0.03714808 & 0.589722431 & 0.930842021 \\
\hline 19 & 0.30358733 & 0.950880227 & 0.69641 & 0.04911977 & 0.417916002 & 0.910548162 \\
\hline 20 & 0.527859051 & 0.558014131 & 0.47214 & 0.44198587 & 0.51432871 & 0.530793525 \\
\hline 21 & 0.86064114 & 0.925453159 & 0.13936 & 0.07454684 & 0.782033426 & 0.870251065 \\
\hline 22 & 0.604566849 & 0.931694814 & 0.39543 & 0006830519 & 0.558388976 & 0.879808969 \\
\hline 23 & 0.960692024 & 1.000000000 & 0.03931 & 0.00000000 & 0.927114046 & 1.000000000 \\
\hline 24 & 0.82858415 & 0.878333785 & 0.17142 & 0.12166621 & 0.74469496 & 0.804290129 \\
\hline 25 & 0.808675741 & 0.845948808 & 0.19132 & 0.15405119 & 0.723249609 & 0.764466155 \\
\hline 26 & 0.862422084 & 0.93757834 & 0.13758 & 0.06262166 & 0.784217877 & 0.889012703 \\
\hline 27 & 0.638023152 & 0.972521373 & 0.36198 & 0.02747868 & 0.580061983 & 0.947905705 \\
\hline
\end{tabular}

Taguchi method is used to optimize the process parameters for high quality with low cost. In this technique, $\mathrm{S} / \mathrm{N}$ ratio is used to convert the experimental results in value for the evaluation characteristics to optimum parameter analysis. Larger $\mathrm{S} / \mathrm{N}$ ratio represents a better quality characteristic. The $\mathrm{S} / \mathrm{N}$ ratio is maximized to reduce the effect of random noise factors and to find the effect of significant process parameters. 
Table 7. Grey relational grades and their order.

\begin{tabular}{lccccc}
\hline Sr. No. & Grey relational grade & Order & Sr. No. & Grey relational grade & Order \\
\hline 1 & 0.35324 & 26 & 15 & 0.82047 & 8 \\
2 & 0.69239 & 16 & 16 & 0.53894 & 24 \\
3 & 0.98799 & 1 & 17 & 0.80291 & 9 \\
4 & 0.62668 & 22 & 18 & 0.76028 & 12 \\
5 & 0.83425 & 5 & 19 & 0.66423 & 18 \\
6 & 0.69482 & 15 & 20 & 0.52256 & 25 \\
7 & 0.34771 & 27 & 21 & 0.82614 & 7 \\
8 & 0.68665 & 17 & 22 & 0.7191 & 14 \\
9 & 0.82871 & 6 & 23 & 0.96356 & 2 \\
10 & 0.87073 & 3 & 24 & 0.77449 & 10 \\
11 & 0.66076 & 19 & 25 & 0.74386 & 13 \\
12 & 0.56229 & 23 & 26 & 0.83662 & 4 \\
13 & 0.65581 & 20 & 27 & 0.76398 & 11 \\
14 & 0.62732 & 21 & & & \\
\hline
\end{tabular}

The $\mathrm{S} / \mathrm{N}$ ratio for grey relational grade is calculated using higher-the-better criteria and the equation for higher-the-better is given below,

$$
\frac{S}{N} \text { ratio }=-10 \log \left[\frac{1}{n} \sum \frac{1}{y^{2}}\right]
$$

where ' $y$ ' is the observed data and ' $n$ ' is the number of observations. As the experimental design is orthogonal, it is possible to separate out the effect of each coating parameter at different levels. The mean grey relational grade for three levels of the three factors is summarized in Table 8. All the calculations are performed with the help of Minitab software [32]. The response table shows the average of the selected characteristic for each level of the factors. The ranks shown in the table are based on Delta statistics and it compares the relative magnitude of effects. The Delta statistics is the difference of highest average and lowest average of each factor. Ranks are assigned on the basis of Delta values for, e. g., rank 1 is assigned to the highest Delta value, rank 2 is assigned to next highest value, and so on. The parameter which possesses higher delta value has greater influence over the response. From Table 8, it is confirmed that parameter $\mathrm{D}$ (annealing temperature) possesses the highest delta value; this means that it has the greatest influence on the electrochemical performance of electroless $\mathrm{Ni}$ $\mathrm{P}-\mathrm{TiO}_{2}$ composite coatings. Fig. 6 shows the main effects plot for mean $\mathrm{S} / \mathrm{N}$ ratio and Fig. 7 shows the interaction plots between the process parameters.

Table 8. Mean response table for grey relational grade.

\begin{tabular}{lllll}
\hline Level & $\mathrm{A}$ & $\mathrm{B}$ & $\mathrm{C}$ & $\mathrm{D}$ \\
\hline 1 & 0.67249 & 0.68226 & 0.61337 & 0.60766 \\
2 & 0.69995 & 0.74628 & 0.73634 & 0.79727 \\
3 & 0.75717 & 0.70107 & 0.77991 & 0.72468 \\
Delta & 0.08468 & 0.06402 & 0.16654 & 0.18962 \\
Rank & 3 & 4 & 2 & 1 \\
\hline \multicolumn{2}{l}{ Total mean grey relational grade $=0.70987$} & & & \\
\hline
\end{tabular}




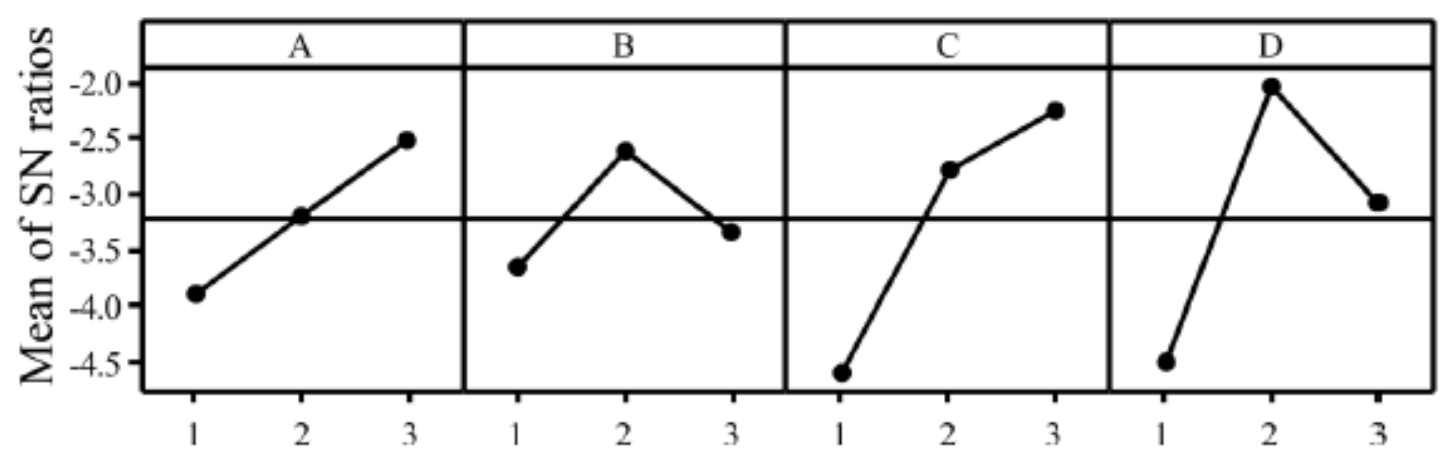

Figure 6. Main effects plot for mean $\mathrm{S} / \mathrm{N}$ ratio.

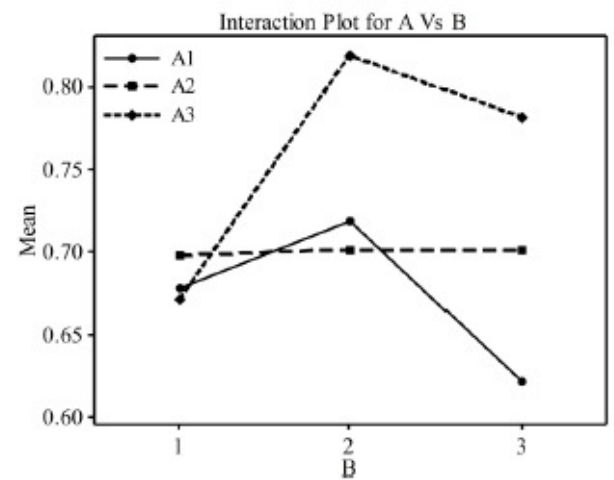

(a)

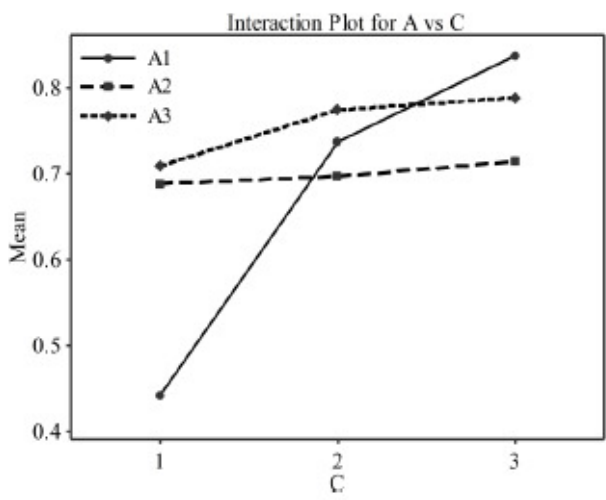

(b)

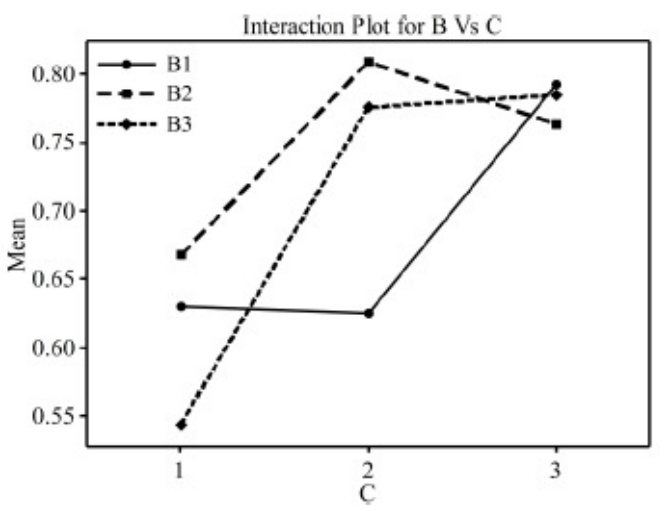

Figure 7. Interaction plots for (a) A vs. B; (b) A vs. C; (c) B vs. C.

The main effects plot gives the optimal combination of the coating process parameters for the desired electrochemical performance. If the line for a particular parameter in the main effect plot is horizontal, it means that the parameter has no significant effect. On the other hand, if the line has maximum inclination to horizontal line, it means that the parameter has the most significant effect. From Fig. 6, it is confirmed that concentration of $\mathrm{TiO}_{2}$ particles (parameter $\mathrm{C}$ ) has the significant effect, annealing temperature (parameter D) has the most significant effect and nickel source (parameter $\mathrm{A}$ ) has the moderate effect. Larger Grey relational grade has better multiresponse characteristics. The optimal combination of parameters was found as A3B2C3D3. Interactions between parameters $\mathrm{A}, \mathrm{B}$ and $\mathrm{C}$ are shown in Fig. 7. From the plots it is 
confirmed that almost all lines are intersecting to each other, i.e., all factors have some amount of interaction between each other. Parameters $A$ and $C$ have the strong interaction and parameters $\mathrm{A}$ and $\mathrm{B}$ have moderate interaction.

ANOVA is used to find the effect of the process parameters and their significance level. ANOVA gives the total variability of the response into contribution of each of the factors and the error. A sophisticated software, Minitab, is used to obtain the results through ANOVA using grey relational grade. ANOVA results for electrochemical behavior of the $\mathrm{TiO}_{2}$ composite coatings are shown in Table 9. These calculations are based on the F-ratio (variance ratio). It is used to measure the significance of the parameters under investigation with respect to variations of all the terms included in the error term at the desired significance level. If the calculated value is higher than the tabulated value it means that the factor is significant at the desired level. From the table it is confirmed that parameter D (annealing temperature) has the most significant effect on the corrosion behaviour at the confidence level of $99 \%$ within the specific test range. The concentartion of $\mathrm{TiO}_{2}$ particels (C) has significant effect at $97.5 \%$ confidence level. Among the interactions, the interaction between parameters $\mathrm{A}$ and $\mathrm{C}$ has the most significant contribution at confidence level of $90 \%$. From ANOVA table it is confirmed that parameter D has the largest contribution (26.35\%) followed by parameter $\mathrm{C}(21.48 \%)$. Among the interactions, interaction $\mathrm{A} \times \mathrm{C}$ has the highest contribution $(20.83 \%)$.

Table 9. Result of ANOVA for electrochemical behavior.

\begin{tabular}{llllll}
\hline Source & DOF & SS & MS & F & \% contribution \\
\hline A & 2 & 0.0336 & 0.0168 & 2.04847 & 5.37386 \\
B & 2 & 0.01949 & $0 . .00974$ & 1.18812 & 3.11717 \\
C & 2 & 0.13427 & 0.06713 & $8.1859^{*}$ & 21.4766 \\
D & 2 & 0.16476 & 0.08238 & $10.0445^{*}$ & 26.3529 \\
AxB & 4 & 0.03049 & 0.000762 & 0.92932 & 4.87633 \\
AxC & 4 & 0.13025 & 0.03256 & $3.97047 *$ & 20.834 \\
BxC & 4 & 0.06313 & 0.01578 & 1.92451 & 10.0983 \\
Error & 6 & 0.04921 & 0.0082 & & 7.87084 \\
Total & 26 & & & 100.0000 \\
\hline *Significant at confidence level $\left(\mathrm{F}_{2,6,0.01}=10.925, \mathrm{~F}_{2,6,0.025}=10.925\right.$ and $\left.\mathrm{F}_{4,6,0.1}=3.1808\right)$ \\
\hline
\end{tabular}

In the last, confirmation test is conducted on the basis of optimum combination of parameters with their respective levels. The predicted values of the grey relational grade at the optimum level $\hat{\eta}$ are calculated as

$$
\widehat{\eta}=\eta_{m}+\sum_{i=1}^{o}\left(\bar{\eta}_{i}-\eta_{m}\right)
$$

where $\eta_{m}$ is the total mean grey relational grade, $\bar{\eta}_{i}$ is the mean grey relational grade at optimal level, and ' $\mathrm{o}$ ' is the number of main design parameters that significantly affect the electrochemical performance of $\mathrm{Ni}-\mathrm{P}-\mathrm{TiO}_{2}$ composite coating. Table 10 shows results of the confirmation test. The increase of the grey 
relational grade from the initial condition (A2B2C2D2) to the optimal condition (A3B2C3D3) was found as 0.17576 , which is more than $29.356 \%$ of the mean grey relational grade. It means that the corrosion resistance improved significantly.

Table 10. Result of the confirmation test.

\begin{tabular}{llll}
\hline & Initial condition & \multicolumn{2}{c}{ Optimum condition } \\
\cline { 3 - 4 } & & Prediction & Experimentation \\
\hline Level & A2B2C2D2 & A3B2C3D3 & A3B2C3D3 \\
Corrosion potential $(\mathrm{mV})$ & -394.38 & & -336.41 \\
Corrosion current density $\left(\mu \mathrm{A} / \mathrm{cm}^{2}\right)$ & 0.0004353 & & 0.0002869 \\
Grade & 0.59873 & 0.867 & 0.77449 \\
\hline
\end{tabular}

Improvement of grey relational grade $=0.17576$

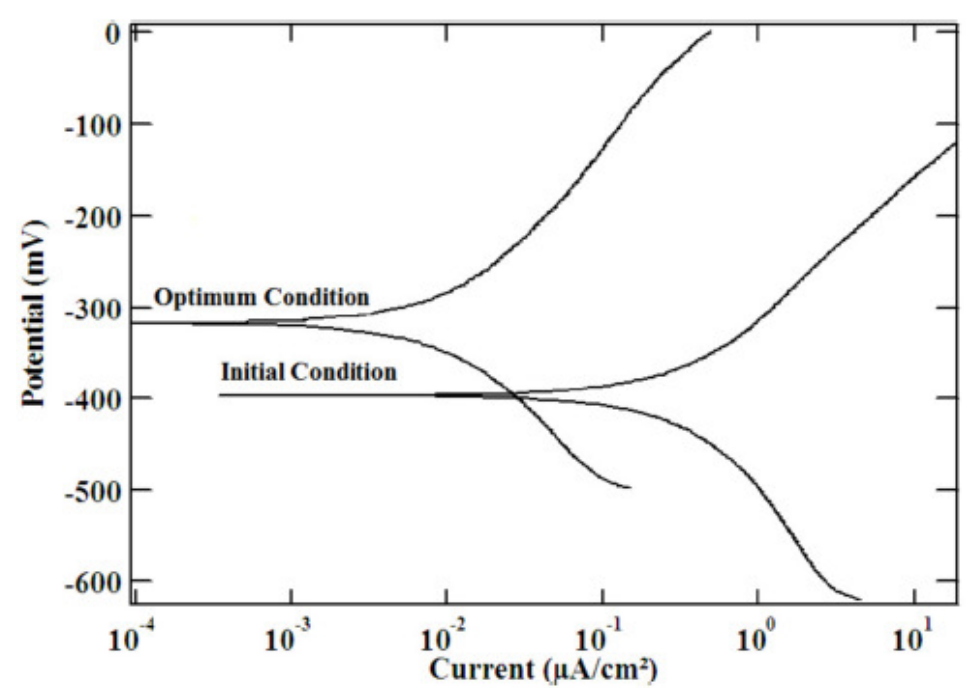

Figure 8. Polarization curves for initial and optimum condition for $\mathrm{TiO}_{2}$ composite coatings.

The polarization curves for the $\mathrm{Ni}-\mathrm{P}-\mathrm{TiO}_{2}$ composite coatings at initial and optimal condition are shown in Fig. 8. The polarization curves do not exhibit any passive behaviour. The corrosion potential and corrosion current density of the $\mathrm{TiO}_{2}$ composite coatings improved from initial condition $(-394.38 \mathrm{mV})$ to optimum condition $(-336.41 \mathrm{mV})$.

\section{Conclusions}

In the present study Taguchi method combined with grey relational analysis has been used to optimize the coating process parameters in order to improve the chemical behavior of $\mathrm{Ni}-\mathrm{P}-\mathrm{TiO}_{2}$ composite coating. The electrochemical tests were conducted using potentiodynamic polarization in $3.5 \% \mathrm{NaCl}$ solution. The optimum parameters combination was found as, higher level of nickel sulphate (45 g/L), middle level of sodium hypophosphite $(20 \mathrm{~g} / \mathrm{L})$, higher level of $\mathrm{TiO}_{2}$ particles $(15 \mathrm{~g} / \mathrm{L})$, and higher level of annealing temperature $\left(500{ }^{\circ} \mathrm{C}\right)$ (A3B2C3D3). From ANOVA results it is confirmed that annealing temperature and concentration of $\mathrm{TiO}_{2}$ particles have significant influence on the 
electrochemical behavior of the composite coating. The interaction between nickel source and concentration of $\mathrm{TiO}_{2}$ particles has the most significant influence among the interactions. The improvement in grey relational grade from the initial condition to the optimal condition has been found as $29.356 \%$. From the EDX analysis it is confirmed that the coated layer embedded with titanium particles and consists of nickel, phosphorous, and oxygen. The SEM micrographs revealed that the coating has cauliflower like structure with uniform distribution of titanium particles. From XRD plots it is confirmed that the as-deposited coating has amorphous structure and the heat treated composite coating has crystalline structure. The coating deposited using the optimum combination has excellent corrosion resistance compared to the coating deposited using initial condition.

\section{Reference}

1. Riedel W. Electroless Nickel Plating. Ohio, USA. ASM International, Metal Park; 1991.

2. Sahoo P, Das SK. Mater Design. 2011;32:1760.

3. Sudagar J, Lian J, Sha W. J Alloys Compounds. 2013;571:183.

4. Agarwala RC, Agarwala V. Sadhana. 2003;28:475.

5. Sharma A, Singh A K. J Mater Eng Performance. 2013; 22: 176.

6. Praveen BM, Venkatesha TV, Naik YA, et al. Surf Coat Technol. 2007;201:5836.

7. Lee CK. Int J Electrochem Sci. 2012;7:8487.

8. Hosseini J, Bodaghi A, Port Electrichim Acta. 2013;31:1.

9. Novakovic J, Vassiliou P, Samara Kl, et al. Surf Coat Technol. 2006;201:895.

10. Momenzadeh M, Sanjabi S, Mater Corrosion. 2012;63:614.

11. Malfatti CF, Ferreira JZ, Santos CB, et al. Corrosion Sci. 2005;47:567.

12. Rabizadeh T, Allahkaram SR. Mater Design. 2011;32:133.

13. Zarebidaki A, Allahkaram SR. Micro Nano Letters. 2011;6:937.

14. Zarebidaki A, Allahkaram SR. Micro Nano Letters. 2012;7:907.

15. Lee CK. Int J Electrochem Sci. 2012;7:12941.

16. Liu Y. Corrosion Sci. 2005;47:2807.

17. Ranganatha S, Venkatesha TV, Vathsala K. Appl Surf Sci. 2010;256:7377.

18. Bigdeli F, Allahkaram SR. Mater Design. 2009;30:4450.

19. Leon C, Gracia-Ochoa E, Gracia-Guerra J, et al. Surf Coat Technol. 2010;205:2425.

20. Balaraju JN, Sankara Narayanan TSN, Seshadri SK. J Solid State Electrochem. 2001;5:334.

21. Song L, Wang Y, Lin W, et al. Surf Coat Technol. 2008;202:5146.

22. Mafi IR, Dehghanian C. Appl Surf Sci. 2011;257:8653.

23. Liu D, Yan Y, Lee K, et al. Mater Corrosion. 2009;60:690.

24. Xu H, Yang Z, Li MK, et al. Surf Coat Technol. 2005;191:161.

25. Liu D, Yan Y, Lee K, et al. Mater Corrosion. 2009;60:690.

26. Das SK, Sahoo P. Tribology. 2011;5:16. 
27. Roy S, Sahoo P. J Coatings. 2013. In press. DOI: 10.1155/2013/6081140.

28. Gadhari P, Sahoo P. Appl Mechanics Mater. 2014;592-594:1300.

29. Gadhari P, Sahoo P. Port Electrochim Acta. 2014;32:137.

30. Roy RK. A primer on the Taguchi method, Society of Manufacturing Engineers. Mich, USA. Dearborn; 1990.

31. Deng J. J Grey System. 1989;1:1.

32. Minitab user manual (release 13.2), Making data analysis easier, MINITAB Incorporation, State College, PA, USA. 2001. 